\title{
Evaluation of the learning curve for totally robotic single-anastomosis duodenal-ileal bypass with sleeve gastrectomy by CUSUM analysis
}

\section{Lun Wang}

China-Japan Union Hospital, Jilin University

\section{Zeyu Wang}

China-Japan Union Hospital, Jilin University

Tao Jiang ( $\nabla$ jiangtao99@jlu.edu.cn )

China-Japan Union Hospital, Jilin University

\section{Research Article}

Keywords: SADI-S, surgical success, laparoscopy, BPD/DS, sleeve gastrectomy (SG), RYGB, Textbook Outcome

Posted Date: July 9th, 2021

DOI: https://doi.org/10.21203/rs.3.rs-681528/v1

License: (c) (i) This work is licensed under a Creative Commons Attribution 4.0 International License. Read Full License 


\section{Abstract}

Single-anastomosis duodenal-ileal bypass with sleeve gastrectomy (SADI-S) has similar efficacy and lower complication rate in the treatment of morbid obesity and obesity-associated metabolic diseases compared with the biliopancreatic diversion with a duodenal switch. The use of a robotic surgical system reduces surgical difficulties and improves surgical outcomes. The learning curve reflects the rate of skills or knowledge acquired in a certain period of time. However, the learning curve for robotic SADI-S has not been estimated.We used the cumulative sum analysis method to investigate the learning curve of totally robotic SADI-S. Textbook outcome analysis was performed to comprehensively define surgical success or failure.Multivariate analysis was performed to predict independent risk factors for complications and operative time. The moving average method was used to reflect the trends in operative time.This study showed that the learning curve for totally robotic SADI-S was 27 cases. Surgeon experience (case number and successful case number) was an independent predictor of the total operative time. A successful case number was the only independent predictor of surgical success or failure in this study $(\beta=0.084 ; P=$ 0.001). Except for the first assistant level, scrubbed nurse level, operative time, and proportion of abdominal drainage tube, there was no significant difference between the learning stage and mastery stage groups. The learning curve for totally robotic SADI-S was 27 cases. Surgeon experience including case number and successful case number were identified as independent predictors affecting the total operative time. A successful case number was the only independent predictor of surgical success or failure.

\section{Introduction}

Bariatric and metabolic surgery-evolved from laparotomy to the laparoscopic approach-is switching to a robot surgical system. Compared with conventional laparoscopy, the robotic surgical system offers several advantages ${ }^{[1-7]}$, including 7 degrees of freedom, tremor filtration, three-dimensional highdefinition visualization, and superior ergonomics, which increase surgical safety and improve surgical outcomes. Since Cadiere reported the world's first robotic bariatric surgery in 1999, the robotic surgical system is being used in various bariatric procedures such as sleeve gastrectomy (SG), Roux-en-Y gastric bypass (RYGB), and biliopancreatic diversion with duodenal switch (BPD/DS); several studies have reported the learning curve for SG, RYGB, and BPD/DS ${ }^{[8-11]}$. Single-anastomosis duodenal-ileal bypass with sleeve gastrectomy (SADI-S) is being used for the treatment of morbid obesity for 14 years since it was first proposed by Torres et al. in 2007 ${ }^{[12]}$. SADI-S has been recommended by the International Federation for the Surgery of Obesity and Metabolic Disorders in the treatment of morbid obesity and obesity-related metabolic diseases ${ }^{[13]}$. However, only a few studies are present on robotic SADI-S ${ }^{[14-17]}$. Moreover, the learning curve for robotic SADI-S has not been estimated. Therefore, this study aimed to estimate the learning curve for totally robotic SADI-S.

\section{Methods}




\section{Patient and Clinical Data}

Seventy-one consecutive patients undergoing totally robotic SADI-S between March 2020 and April 2021 were included in this study. All the surgeries were performed by the same surgeon. We recorded and analyzed the following factors: patient gender, age, preoperative body weight, body mass index, waistline, standard live volume, American Society of Anesthesiology Physical Status Classification, operative time, first assistant level, scrubbed nurse level, number of staplers used, the proportion of abdominal drainage tube, length of postoperative stay, complications (30-day), conversion to laparotomy, mortality, reoperation, and readmission within 30 days. The Dindo-Clavien classification was used to classify the severity of complications ${ }^{[18]}$. This research including all experimental methods was approved by the ethics committee of the China-Japan Union Hospital of Jilin university,and informed consent was obtained from all participants. All procedures performed in studies involving human participants were carried out in accordance with the ethical standards of the institutional and/or national research committee and with the 1964 Helsinki Declaration and its later amendments or comparable ethical standards.

\section{Operative Technique}

The Da Vinci Xi® model was used for totally robotic SADI-S. The patient undergoing surgery was in reverse Trendelenburg position with open legs and arms. The first trocar for the $30^{\circ}$ camera $(8 \mathrm{~mm}$, robotic arm 3) was placed at the lower edge of the navel. Other trocars were inserted under visual inspection. The second trocar for the stapler insertion (12-mm, robotic arm 1) was placed at the junction of the right anterior axillary line and right end of the greater curvature of the stomach. The third trocar for liver retractor ( $8 \mathrm{~mm}$, robotic arm 2) was placed at the junction of the right midclavicular line and costal margin. The fourth trocar (8-mm, robotic arm 4) was placed at the junction of the left midclavicular line and left end of the greater curvature of the stomach. All the trocars were spaced more than $8 \mathrm{~cm}$, avoiding each other's interference of robotic arms. A 300-cm common channel was measured retrograde from the ileocecal valve and marked by sutures. SG was performed about $4 \mathrm{~cm}$ from the pylorus over a $34 \mathrm{Fr}$ bougie tube. Complete duodenum transection was performed about $2 \mathrm{~cm}$ from the pylorus. Finally, duodenal-ileal anastomosis was performed continuously by using an absorbable $3-0$ barbed suture.

\section{Definitions}

According to a review of existing "Textbook Outcome" metrics in the literature ${ }^{[19-23]}$, the definition of surgical failure was subsequently expanded for totally robotic SADI-S-specific outcomes selected based on clinician consensus among a team of bariatric surgeons at our institution. The final definition of surgical failure in totally robotic SADI-S included the following 5 key parameters: operative time $>210$ min, length of postoperative stay $>7$ days, postoperative morbid event $\geq$ Clavien grade II, conversion to laparotomy, and rehospitalization or death after totally robotic SADI-S. Surgical failure was recorded when any of the aforementioned parameters were observed. The level of the surgeon, first assistant, and scrubbed nurse was represented as the number of totally robotic SADI-S they participated in. 
The CUSUM analysis method and best-fit model were used to estimate the learning curve for totally robotic SADI-S. This method was used for all study cases considering operative time. First, all the patients were numbered from 1 to 71 on the basis of the earliest to the latest date of surgery and then, the CUSUM value of operative time for each case was calculated using the formula mentioned below ${ }^{[24]}$. The scatter plot on the learning curve of totally robotic SADI-S was drawn by case number as X-axis and CUSUM (operative time) as Y-axis. The IBM ${ }^{\circledR}$ SPSS ${ }^{\circledR}$ Statistics software version 22.0 is used to fit the learning curve. The fitting model test is judged by the $P$ value, and $P \otimes 0.05$ means that the fitting of learning curve is successful. The goodness-of-fit is judged by the coefficient of determination (R2). The closer to the 1 for R2 value, the higher the goodness-of-fit. The model with the largest R2 value will be selected as the best fitting model. The peak of the CUSUM curve was considered as the end of the learning process. Based on the peak of the CUSUM curve, each patient was classified into either the learning stage group or the mastery stage group.

$$
\text { CUSUM } \square \text { OperativeTime } \square=\sum_{k=1}^{n}(\mathrm{Xi}-\mu)
$$

(Xi: the operative time for the corresponding patient; $\mu$ : the mean operative time for all cases; $\mathrm{n}$ : the casenumber)

\section{Moving Average Method}

The moving average method is a simple, smoothing, forecasting technique. According to time series, sequential time averages containing a certain number of items are sequentially calculated by item by item to reflect the long-term trend [25]. We employed the moving average method to calculate the operative time of totally robotic SADI-S using the formula mentioned below:

$$
\operatorname{SMA}(\mathrm{n})=\frac{\mathrm{Xn}+\mathrm{Xn}-1+\mathrm{Xn}-2++\mathrm{Xn}-13}{14}
$$

\section{Statistical Analysis}

SPSS 22.0 was used for statistical analysis. Measurement data were expressed as mean \pm standard deviation and were analyzed by the independent-sample Student's t-test (Normality data) or MannWhitney U test (skewed data), as appropriate. The calculated data were analyzed by the Chi-square test. A $P$ value of $<0.05$ was considered statistically significant.

\section{Results}

Seventy-one consecutive patients undergoing totally robotic SADI-S were included in this study and the overall follow-up rate was $100 \%$. Among the 71 patients, 42 were women and 29 were men with a mean age of 33.65 years (range, 18-59 years). The patient demographic data are summarized in Table 1. 
Table 1

Patient demographics

\begin{tabular}{|ll|}
\hline Factor & All patients $(\mathbf{n}=\mathbf{7 1})$ \\
\hline Gender: Male/Female & $29 / 42$ \\
\hline Mean age (years) & $33.65 \pm 8.67$ \\
\hline Preoperative body weight $(\mathrm{kg})$ & $123.20 \pm 26.89$ \\
\hline Preoperative BMI $\left(\mathrm{kg} / \mathrm{m}^{2}\right)$ & $42.16 \pm 7.15$ \\
\hline Preoperative waistline $(\mathrm{cm})$ & $127.25 \pm 16.32$ \\
\hline Previous upper abdominal surgery & 0 \\
\hline ASA Classification & $45(66.1 \%)$ \\
\hline Grade II & $26(33.9 \%)$ \\
\hline Grade III & \\
\hline ASA Classification: American Society of Anesthesiology Physical Status classification. \\
\hline
\end{tabular}

The best fitting equation of learning curve for totally robotic SADI-S was as follows: CUSUM (operative time $)=96.21 \otimes 38.75 X-1.21 X^{2} \otimes 9.25 E-3 X^{3}(X$ is surgical case number). The $P$ value of fitting model test was 0.000 , which meant that the fitting of learning curve was successful. The coefficient of determination (R2) was 0.933 , which represented the goodness-of-fit was excellent. The CUSUM (operative time) of learning curve reached its peak when the number of surgical cases accumulated to the 27th case.This suggests that the learning curve for totally robotic SADI-S in a CUSUM manner was 27 cases(Fig. 1). Subsequently, all the patients were classified into the learning stage group (the first 27 patients) and the mastery stage group (the last 44 patients). No significant difference was observed between the two groups in terms of patient demographic data (Table 2). The operation-related parameters such as the number of staplers in SG, complications, reoperations, readmission, and postoperative hospital stay were similar in both groups (Table 3). However, the first assistant level and the scrubbed nurse level were significantly less in the learning stage group compared with the mastery stage group (Table 3 ). Moreover, operative time and proportion of abdominal drainage tubes were also significantly higher in the learning stage group compared with the mastery stage group (Table 3 ). The operative time on the moving average curve decreased throughout the study period. However, the slope was more pronounced in the learning stage group (until 27th case) than the mastery stage group (Fig. 2). 
Table 2

Comparison of the demographics between the 2 study groups

\begin{tabular}{|c|c|c|c|c|}
\hline & $\begin{array}{l}\text { Learning stage } \\
\text { group } \\
(n=27)\end{array}$ & $\begin{array}{l}\text { Mastery stage } \\
\text { group } \\
(n=44)\end{array}$ & Statistic & $\begin{array}{l}P \\
\text { value }\end{array}$ \\
\hline Gender (Male/Female) & $10 / 17$ & $19 / 25$ & $\chi 2=0.261$ & 0.609 \\
\hline Age (years) & $33.41 \pm 9.21$ & $33.78 \pm 8.43$ & $\begin{array}{l}U= \\
594.000\end{array}$ & 1.000 \\
\hline $\begin{array}{l}\text { Preoperative body weight } \\
\text { (kg) }\end{array}$ & $121.37 \pm 28.27$ & $124.32 \pm 26.28$ & $t=-0.446$ & 0.657 \\
\hline Preoperative BMI (kg/m²) & $41.92 \pm 6.93$ & $42.30 \pm 7.35$ & $t=-0.220$ & 0.826 \\
\hline Preoperative waistline (cm) & $126.56 \pm 13.94$ & $127.68 \pm 17.76$ & $t=-0.281$ & 0.780 \\
\hline Standard live volume $\left(\mathrm{cm}^{3}\right)$ & $1605.01 \pm 214.97$ & $1635.71 \pm 189.53$ & $t=-0.629$ & 0.531 \\
\hline $\begin{array}{l}\text { ASA Classification } \\
\text { (grade II/grade III) }\end{array}$ & $17 / 10$ & $28 / 16$ & $x^{2}=0.003$ & 0.954 \\
\hline
\end{tabular}


Table 3

Comparison of the operation-related outcomes between the 2 study groups

\begin{tabular}{|c|c|c|c|c|}
\hline & $\begin{array}{l}\text { Learning stage } \\
\text { group } \\
(n=27)\end{array}$ & $\begin{array}{l}\text { Mastery stage } \\
\text { group } \\
(n=44)\end{array}$ & Statistic & $\begin{array}{l}P \\
\text { value }\end{array}$ \\
\hline Operative time(min) & $202.22 \pm 36.86$ & $171.52 \pm 30.13$ & $\begin{array}{l}U= \\
297.500\end{array}$ & 0.000 \\
\hline Number of staplers in SG & $6.04 \pm 1.06$ & $5.89 \pm 0.84$ & $\begin{array}{l}U= \\
575.500\end{array}$ & 0.811 \\
\hline First assistant level & $7.93 \pm 5.87$ & $25.18 \pm 14.27$ & $\begin{array}{l}U= \\
178.500\end{array}$ & 0.000 \\
\hline Level of scrubbed nurse & $2.33 \pm 1.75$ & $4.95 \pm 3.77$ & $\begin{array}{l}U= \\
301.500\end{array}$ & 0.000 \\
\hline Complications overall & $3(9.7 \%)$ & $4(9.1 \%)$ & $x 2=0.000$ & 1.000 \\
\hline Conversion to laparotomy & 0 & 0 & - & - \\
\hline Reoperations & $1(3.7 \%)$ & $1(2.3 \%)$ & 0.000 & 1.000 \\
\hline Readmission & $1(3.2 \%)$ & 0 & - & 0.380 \\
\hline Mortality & 0 & 0 & - & - \\
\hline Abdominal drainage tube & $20(74.1 \%)$ & $8(18.2 \%)$ & $\begin{array}{l}\chi 2= \\
21.885\end{array}$ & 0.000 \\
\hline $\begin{array}{l}\text { Postoperative hospital } \\
\text { stay(days) }\end{array}$ & $6.70 \pm 2.05$ & $7.82 \pm 8.05$ & $\begin{array}{l}U= \\
505.500\end{array}$ & 0.270 \\
\hline
\end{tabular}

Overall, mortality and conversion to laparotomy did not occur in this study. Seven patients $(9.9 \%)$ suffered through complications, including two with gastric leakage (2.8\%), one with duodenal-ileal anastomotic leakage (1.4\%), one with postoperative acute respiratory failure (1.4\%), one with postoperative abdominal bleeding (1.4\%), one with seroperitoneum $(1.4 \%)$, and one with delayed gastric emptying (1.4\%). The rates of reoperation and readmission were $2.8 \%$ and $1.4 \%$, respectively. Four patients suffered through grade II complications classified on the basis of the Dindo-Clavien classification (one with seroperitoneum, one with postoperative abdominal bleeding, one with delayed gastric emptying, and one with duodenal-ileal anastomotic leakage), and all of them were cured successfully by the conservative treatment. Two patients suffered from gastric leakage (grade IIIb) and required reoperation. One patient was transferred to the intensive care unit because of postoperative acute respiratory failure (grade IV) and was eventually cured.

Multivariate analysis identified surgeon experience (case number and successful case number) as the Loading [MathJax]/jax/output/CommonHTML/fonts/TeX/fontdata.js r, successful case number was found to be the 
only independent predictor of surgical success or failure $(\beta=0.084 ; P=0.001)$. The comparison of patient demographic data between the successful and unsuccessful surgery groups is shown in Table 5 . The patient demographic data between the successful surgery group and the unsuccessful surgery group was not significantly different (Table 5). Therefore, the patient demographic data is not correlated with the success of the surgery.

Table 4

Multivariate analysis for the operation time

\begin{tabular}{|c|c|c|c|c|}
\hline Risk Factor & $\beta$ & $95 \%$ lower & $95 \%$ upper & $P$ value \\
\hline Sex & 0.266 & -1.019 & 39.523 & 0.062 \\
\hline Age & 0.011 & -1.049 & 1.139 & 0.934 \\
\hline Body weight & 1.028 & -3.130 & 5.873 & 0.544 \\
\hline Waistline & -0.138 & -1.244 & 0.638 & 0.521 \\
\hline BMI & -0.033 & -6.525 & 6.193 & 0.959 \\
\hline ASA Classification & 0.036 & -15.048 & 20.427 & 0.763 \\
\hline Numbers of staplers in SG & 0.160 & -2.074 & 14.517 & 0.139 \\
\hline First assistant level & 0.025 & -0.555 & 0.654 & 0.870 \\
\hline Level of scrubbed nurse & -0.231 & -4.999 & 0.102 & .060 \\
\hline Standard live volume & -0.684 & -0.563 & 0.316 & 0.576 \\
\hline Case number & -2.878 & -8.320 & -1.688 & 0.004 \\
\hline Successful case number & 2.605 & 2.009 & 11.599 & 0.006 \\
\hline \multicolumn{5}{|c|}{$\begin{array}{l}\text { ASA Classification: American Society of Anesthesiology Physical Status classification. BMI: Body } \\
\text { mass index. }\end{array}$} \\
\hline \multicolumn{5}{|c|}{$\begin{array}{l}\text { SG: Sleeve gastrectomy. The definition of successful case in totally robotic SADI-S included freedom } \\
\text { from the following factors: operative time }>210 \text { min, the length of postoperative stay }>7 \text { days, } \\
\text { postoperative morbid event } \geq \text { Clavien grade II, conversion to laparotomy, and rehospitalization or } \\
\text { death after totally robotic SADI-S. }\end{array}$} \\
\hline
\end{tabular}


Table 5

Comparison of the demographics between the successful group and the unsuccessful group

\begin{tabular}{|c|c|c|c|c|}
\hline & $\begin{array}{l}\text { Unsuccessful group ( } \mathrm{n} \\
=25)\end{array}$ & $\begin{array}{l}\text { Successful group ( } n \\
=46)\end{array}$ & Statistic & $\begin{array}{l}P \\
\text { value }\end{array}$ \\
\hline Gender (Male/Female) & $11 / 14$ & $18 / 28$ & $\begin{array}{l}\chi 2= \\
0.159\end{array}$ & 0.690 \\
\hline Age (years) & $33.16 \pm 8.59$ & $33.91 \pm 8.80$ & $\begin{array}{l}U= \\
563.500\end{array}$ & 0.890 \\
\hline $\begin{array}{l}\text { Preoperative body weight } \\
\text { (kg) }\end{array}$ & $125.84 \pm 27.16$ & $121.76 \pm 26.73$ & $t=0.608$ & 0.545 \\
\hline Preoperative BMI $\left(\mathrm{kg} / \mathrm{m}^{2}\right)$ & $43.12 \pm 6.74$ & $41.64 \pm 7.38$ & $t=0.703$ & 0.408 \\
\hline $\begin{array}{l}\text { Preoperative waistline } \\
(\mathrm{cm})\end{array}$ & $129.28 \pm 13.56$ & $126.15 \pm 17.68$ & $t=0.832$ & 0.409 \\
\hline $\begin{array}{l}\text { Standard live volume } \\
\left(\mathrm{cm}^{3}\right)\end{array}$ & $163898 \pm 198.46$ & $1615.92 \pm 200.45$ & $t=0.465$ & 0.644 \\
\hline $\begin{array}{l}\text { ASA Classification } \\
\text { (grade II/grade III) }\end{array}$ & $16 / 9$ & $29 / 11$ & $\begin{array}{l}x 2= \\
0.006\end{array}$ & 0.936 \\
\hline \multicolumn{5}{|c|}{$\begin{array}{l}\text { ASA Classification: American Society of Anesthesiology Physical Status classification. BMI: Body } \\
\text { mass index. }\end{array}$} \\
\hline \multicolumn{5}{|c|}{$\begin{array}{l}\text { The definition of successful case in totally robotic SADI-S included freedom from the following } \\
\text { factors: operative time }>210 \text { min, the length of postoperative stay }>7 \text { days, postoperative morbid } \\
\text { event } \geq \text { Clavien grade II, conversion to laparotomy, and rehospitalization or death after totally robotic } \\
\text { SADI-S. }\end{array}$} \\
\hline
\end{tabular}

\section{Discussion}

SADI-S is being used as a surgical procedure in the treatment of morbid obesity for 14 years since it was first proposed in 2007 by Torres et al. as a simplified procedure of BPD/DS [12]. SADI-S is preferred over $\mathrm{BPD} / \mathrm{DS}$ because of the reduced operative risk by eliminating one anastomosis and similar weight loss and remission of metabolic diseases. Nonetheless, SADI-S has some technical challenges; large waistline, large liver, thick abdominal walls, and substantial visceral fat make exposure, dissection, and reconstruction difficult. Among laparoscopic SADI-S, duodenoileostomy is the most challenging, which requires advanced laparoscopic skills, including suturing and intracorporeal knot tying. These skills are difficult to master because of laparoscopic limitations such as a two-dimensional view and a limited range for instrument movement. Compared with conventional laparoscopy, the robotic surgical system offers several advantages ${ }^{[1-7]}$ including 7 degrees of freedom, tremor filtration, three-dimensional highdefinition visualization, and superior ergonomics, which increase surgical safety and improve surgical outcomes. Using a robotic system, surgeons can easily and precisely perform a 2-layer hand-sewn 
duodenoileostomy, avoid circular stapler use, eliminate the difficulties and risks in anvil introduction, and decrease the stricture rates as gastrojejunostomy during gastric bypass ${ }^{[26]}$.

To our knowledge, this study is the first to estimate the learning curve for robotic SADI-S. According to our results, the learning curve of totally robotic SADI-S is 27 cases and can be divided into Phase 1 and Phase 2. Phase 1 includes the first 27 patients and represents the initial learning stage. Phase 2 represents the mastery stage, with a significant reduction in the operative time and proportion of abdominal drainage tube, and a significant increase in the first assistant level and scrubbed nurse level. The learning curve for other bariatric procedures has been reported previously. Previous studies ${ }^{[9,27]_{\text {have }}}$ shown that the learning curve for robotic $S G$ is $20-25$ cases. The learning curve for robotic RYGB ranged from 14 to 84 cases ${ }^{[10,28-32]}$. Sudan et al. ${ }^{[11]}$ reported that the learning curve for robot-assisted BPD/DS was 50 cases. The learning curve depends on various parameters including the surgeon's skill level, assistant surgeon, scrubbed nurse, ancillary staff, procedure complexity, and patient-related risk factors. In this study, by multifactorial analysis, we analyzed independent risk factors that may affect the learning curve for totally robotic SADI-S. The results indicated that the independent predictor affecting the total operative time was the surgeon's experience (including case number and successful case number). Our results are consistent with the results reported previously ${ }^{[11,29]}$. Therefore, surgeons assisting in robotic SADI-S need to receive professional robotic training to successfully pass phase 1 of the learning curve.

The mean total operative time in this study was 183.19 min, which is within the range of those reported previously for robotic SADI-S (145-204 min) ${ }^{[14-17]}$. An increase in surgeon's proficiency with the increase in surgical experience was reflected in the operative time required; of note, the slope was more pronounced in the learning phase.

This study showed that totally robotic SADI-S is a feasible and safe surgical approach for morbid obesity. A total of 7 patients developed complications (9.9\%), including seroperitoneum (grade II), delayed gastric emptying (grade II), abdominal bleeding (grade II), duodenal-ileal anastomotic leakage (grade II), gastric leakage (2-grade IIIb), and postoperative acute respiratory failure (grade IV). In addition to two patients with gastric leakage (grade IIIb) requiring reoperation, the other 5 patients with the complications were cured by the respective treatment. In general, surgeons are concerned about a higher complication rate during the initial learning phase of the learning curve, wherein they plan to develop a new procedure. In this study, no statistical difference was observed in terms of morbidity between the first 27 patients (learning stage) and the last 44 patients (mastery stage) $(9.7 \%$ vs. $9.1 \% ; P=1.000)$. Thus, totally robotic SADI-S for patients with obesity is completely safe even during the initial phase of the learning curve.

The main limitation of robotic surgery is the perceived higher cost compared with that of laparoscopy. Most previous studies reported that the use of a robotic surgical system increases the cost of the procedure ${ }^{[32-34]}$. However, Hagen et al. ${ }^{[35]}$ reported that the overall cost of robotic RYGB is less compared with laparoscopy. We did not analyze the cost in our study; however, more safety may equalize higher cost. Moreover, the cost of robotic surgery is not necessarily higher than conventional laparoscopy 
This study is the first to report the learning curve for totally robotic SADI-S. However, the study has some limitations. On the one hand, it was a retrospective study. One the other hand, the cost of robotic SADI-S was not analyzed. Randomized controlled trials using large sample sizes are required for further study.

\section{Conclusion}

The learning curve for totally robotic SADI-S was 27 cases. Surgeon experience (case number and successful case number) affected the total operative time more than other factors. Concerning a composite event defining surgical success or failure, successful case number was the only independent predictor identified in this study.

\section{Declarations}

\section{Author contributions}

L.W. and T.J. participated in the design of the study and helped to draf the manuscript. ZY.W. performed the statistical analysis and helped to draf the manuscript. All authors reviewed the manuscript.

\section{Funding}

No funding source.

\section{Competing interests}

The authors declare no competing interests.

\section{Additional information}

Correspondence and requests for materials should be addressed to T.J.

\section{References}

[1].Ayloo S, Fernandes E \& Choudhury N. Learning curve and robot set-up/operative times in singly docked totally robotic Roux-en-Y gastric bypass . Surg Endosc 28, 1629-33(2014).

[2].Heemskerk J, et al. First results after introduction of the four-armed da Vinci Surgical System in fully robotic laparoscopic cholecystectomy. Dig Surg 22, 426-31( 2005).

[3].Ruurda. J P, Visser. P L \& Broeders. I A M J. Analysis of Procedure Time in Robot-Assisted Surgery: Comparative Study in Laparoscopic Cholecystectomy. Computer Aided Surgery 8,24-9(2003).

[4].Delaney CP, Lynch AC, Senagore AJ \& Fazio VW. Comparison of robotically performed and traditional laparoscopic colorectal surgery. Dis Colon Rectum, 46,1633-9(2003). 
[5].Lehnert M, Richter B, Beyer PA \& Heller K. A prospective study comparing operative time in conventional laparoscopic and robotically assisted Thal semifundoplication in children. J Pediatr Surg 41,1392-6(2006).

[6].Jung M, Morel P, Buehler L, Buchs NC\&Hagen ME. Robotic general surgery: current practice, evidence, and perspective. Langenbecks Arch Surg 400,283-92( 2015).

[7].Zarate Rodriguez J G, et al. Ergonomic analysis of laparoscopic and robotic surgical task performance at various experience levels. Surg Endosc 33,1938-43(2019).

[8].Cadiere GB, Himpens J, Vertruyen M\&Favretti F. The world's first obesity surgery performed by a surgeon at a distance. Obes Surg 9, 206-9(1999).

[9].Vilallonga R, et al. The Initial Learning Curve for Robot-Assisted Sleeve Gastrectomy: A Surgeon's Experience While Introducing the Robotic Technology in a Bariatric Surgery Department. Minim Invasive Surg 2012,(347131(2012).

[1]0.Buchs N C, et al. Learning curve for robot-assisted Roux-en-Y gastric bypass. Surg Endosc 26,111621(2012).

[1]1.Sudan R, Bennett KM, Jacobs DO\&Sudan DL. Multifactorial analysis of the learning curve for robotassisted laparoscopic biliopancreatic diversion with duodenal switch. Ann Surg 255, 940-5( 2012).

[12].Sanchez-Pernaute A, et al. Proximal duodenal-ileal end-to-side bypass with sleeve gastrectomy: proposed technique. Obes Surg 17,1614-8(2007).

[13].Brown W A,et al. Single Anastomosis Duodenal-Ileal Bypass with Sleeve Gastrectomy/One Anastomosis Duodenal Switch (SADI-S/OADS) IFSO Position Statement-Update 2020. Obes Surg 31,325(2021).

[14].Tarascó Palomares J, Caballero Boza A, Sánchez Haro E, Herrero Vicente C\& Moreno Santabàrbara P.Really Totally Robotic SADI-S in a Patient with Extreme Morbid Obesity and Non-Reducible Umbilical Hernia: Case Report. Obes Surg 30,4171-3(2020).

[15].Tat C, Del Gobbo GD, Klingler M\&Corcelles R.How I Do It: Robotic Single-Anastomosis Duodeno-lleal Bypass with Sleeve Gastrectomy (SADIS). J Gastrointest Surg 24, 2893-5(2020).

[16].Laviano Martínez E, Lammers L, Goergen M\& Azagra Soria JS. Full Robotic Single Anastomosis Duodeno-ileal bypass (SADI). Cirugía Española (English Edition) 97,535( 2019).

[17].Vilallonga R, et al. Robotically Assisted Single Anastomosis Duodenoileal Bypass after Previous Sleeve Gastrectomy Implementing High Valuable Technology for Complex Procedures. J Obes,2015(586419(2015). 
[18].Dindo D, Demartines N\&Clavien P A. Classification of surgical complications: a new proposal with evaluation in a cohort of 6336 patients and results of a survey. Ann Surg 240, 205-13((2004)).

[19]. Halpern SE, et al. Textbook Outcome: Definition and Analysis of a Novel Quality Measure in Lung Transplantation. Ann Surg. 2021 Apr 9.

[20]. Busweiler LA, et al; Dutch Upper Gastrointestinal Cancer Audit (DUCA) group. Textbook outcome as a composite measure in oesophagogastric cancer surgery. Br J Surg 104,742-750(2017).

[21]. Ten Berge MG, et al; Dutch Lung Cancer Audit for Surgery Group. Textbook outcome as a composite outcome measure in non-small-cell lung cancer surgery. Eur J Cardiothorac Surg 59:92-99(2021). [22].Merath K, et al. A Multi-institutional International Analysis of Textbook Outcomes Among Patients Undergoing Curative-Intent Resection of Intrahepatic Cholangiocarcinoma. JAMA Surg 154,e190571(2019).

[23]. Moris D, et al. Textbook Outcomes in Liver Transplantation. World J Surg 44,3470-3477(2020).

[24].Morató O, Poves I, Burdío F, Sánchez-Velázquez P, Duran X\&Grande L.Evaluation of the learning curve for laparoscopic pancreatoduodenectomy by CUSUM analyses. Cohort study. Int J Surg 80,61-67(2020).

[25].Kim CW,et al. Learning Curve for Single-Incision Laparoscopic Anterior Resection for Sigmoid Colon Cancer. J Am Coll Surg 221,397-403(2015).

[26].Gonzalez R, Lin E, Venkatesh KR, Bowers SP\&Smith CD. Gastrojejunostomy during laparoscopic gastric bypass: analysis of 3 techniques [J]. Arch Surg 138,181-4(2003).

[27].Romero R J, et al. Robotic sleeve gastrectomy: experience of 134 cases and comparison with a systematic review of the laparoscopic approach. Obes Surg 23,1743-52(2013).

[28].Ayloo SM, Addeo P, Buchs NC, Shah G\&Giulianotti PC. Robot-assisted versus laparoscopic Roux-en-Y gastric bypass: is there a difference in outcomes? . World J Surg 35,637-42(2011).

[29].Renaud $M$, et al. Multifactorial analysis of the learning curve for totally robotic Roux-en-Y gastric bypass for morbid obesity. Obes Surg 23,1753-60(2013).

[30].Tieu K, Allison N, Snyder B, Wilson T, Toder M\&Wilson E. Robotic-assisted Roux-en-Y gastric bypass: update from 2 high-volume centers. Surg Obes Relat Dis 9,284-8(2013).

[31].Yu SC, Clapp BL, Lee MJ, Albrecht WC, Scarborough TK\& Wilson EB. Robotic assistance provides excellent outcomes during the learning curve for laparoscopic Roux-en-Y gastric bypass: results from 100 robotic-assisted gastric bypasses. Am J Surg 192,746-9(2006).

[32].Hubens G, Balliu L, Ruppert M, Gypen B, Van Tu T\& Vaneerdeweg W. Roux-en-Y gastric bypass procedure nerformed with the da Vinci rnhat cvctem is it worth it?. Surg Endosc 22,1690-6(2008). Loading [MathJax]/jax/output/CommonHTML/fonts/TeX/fontdata.js 
[33].Curet MJ, Solomon H, Liu G\&Morton JM.Comparison of hospital charges between robotic, laparoscopic stapled, and laparoscopic handsewn Roux-en-Y gastric bypass. J Robot Surg 3, 758(2009).

[34].Scozzari G, Rebecchi F, Millo P, Rocchietto S, Allieta R\& Morino M.Robot-assisted gastrojejunal anastomosis does not improve the results of the laparoscopic Roux-en-Y gastric bypass. Surg Endosc 25,597-603(2011).

[35]. Hagen M E, et al. Reducing cost of surgery by avoiding complications: the model of robotic Roux-en-Y gastric bypass. Obes Surg 22,52-61(2012).

\section{Figures}

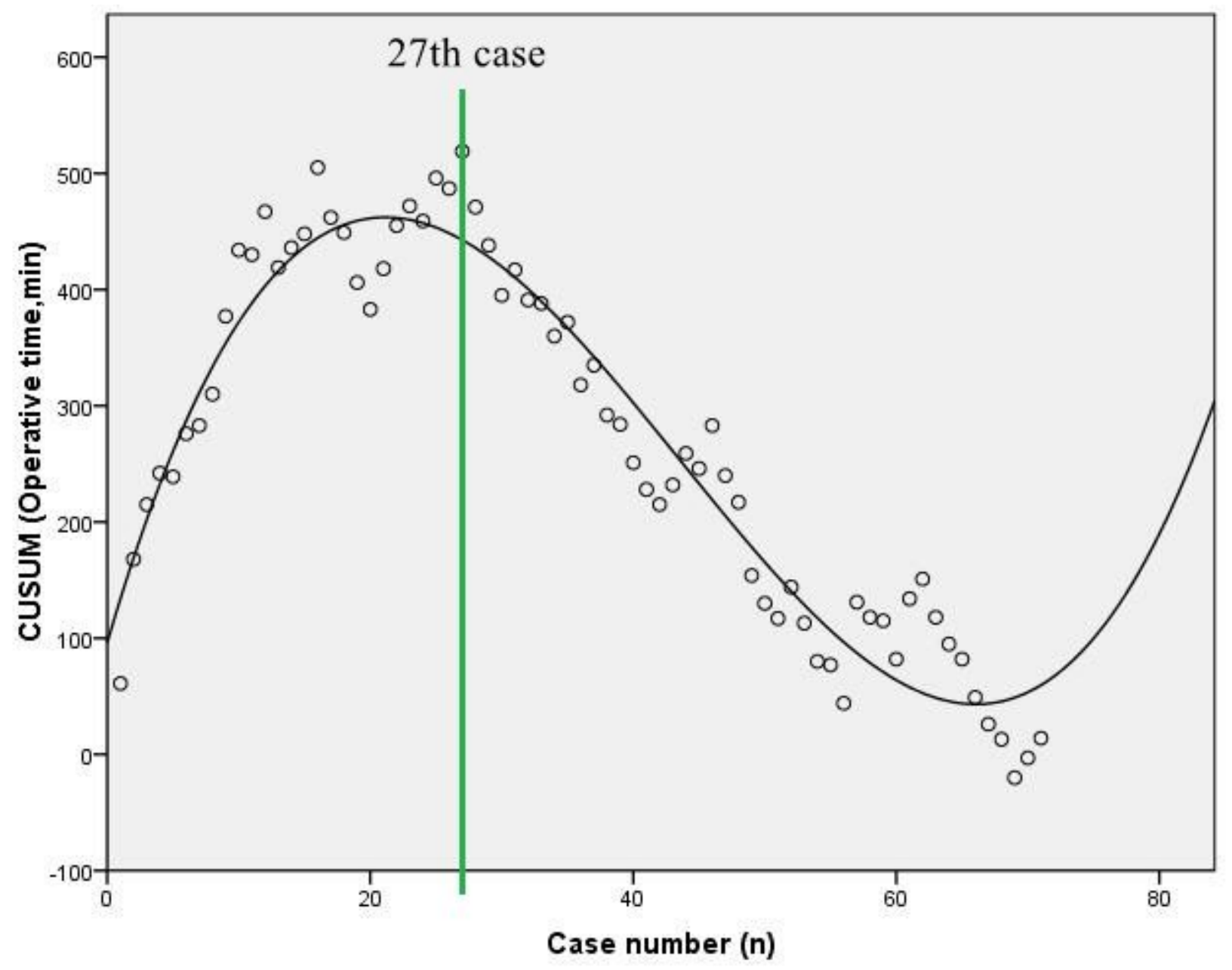

\section{Figure 1}

The CUSUM curve showed that CUSUM value for operative time reached a peak at 27 th case, followed by a rapid decrease. This suggests that the learning curve for totally robotic SADI-S in a CUSUM manner was 27 cases. 


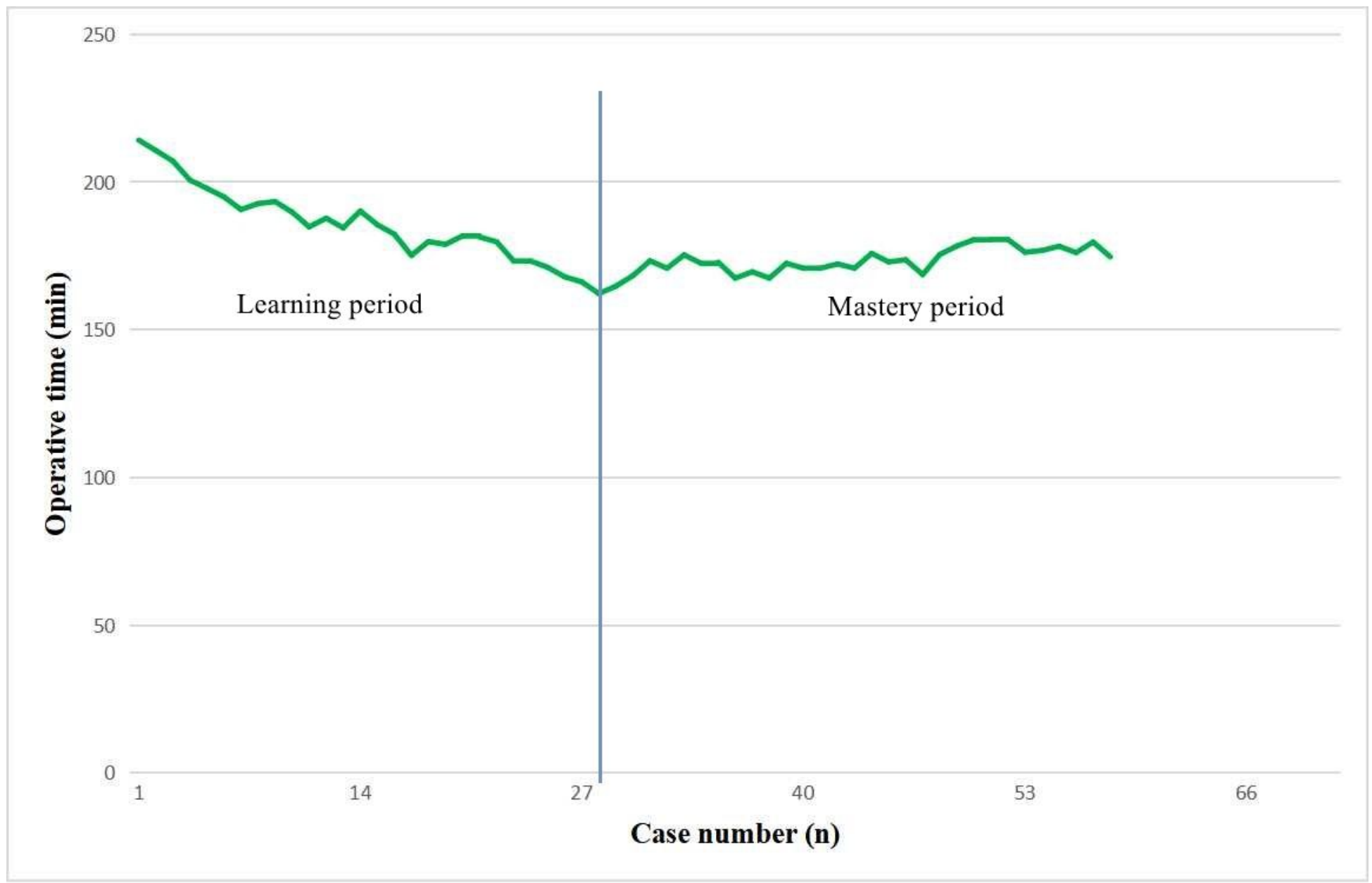

Figure 2

The moving average method for the operation time. The operative time decreased throughout the study period on the moving average curve. However, the slope appeared to be more pronounced during the learning period.

\section{Supplementary Files}

This is a list of supplementary files associated with this preprint. Click to download.

- Table.doc 